\title{
Desain Kapal Ikan di Perairan Laut Selatan Malang
}

\author{
Wildan Alfun Niam, dan Hasanudin. \\ Departemen Teknik Perkapalan, Fakultas Teknologi Kelautan, Institut Teknologi Sepuluh Nopember \\ (ITS) \\ e-mail: hasanudin@na.its.ac.id
}

\begin{abstract}
Abstrak - Potensi perikanan di Perairan Laut Selatan Malang cukup besar. Berdasarkan data hasil tangkapan dapat diketahui bahwa ada beberapa jenis ikan yang ditangkap oleh para nelayan disana seperti tuna, cakalang, tongkol dan lainlain. Akan tetapi, nelayan di pesisir pantai masih menggunakan teknologi yang tradisional. Oleh sebab itu perlu ada pengembangan kapal penangkap ikan beserta alat tangkapnya. Selain memoderenisasi alat tangkap ikan, juga perlu memperhatikan kualitas hasil tangkapan itu sendiri agar memiliki standart kualitas ekspor. Dengan adanya hal ini perlu dipertimbangkan alternatif pola pengoperasional kapal yang dapat meningkatkan kualitas ikan hasil tangkap. Tujuan dari studi ini adalah untuk mendesain sebuah kapal penangkap ikan yang digunakan untuk perairan laut selatan Malang. Perencanaan ukuran kapal ikan, data utama kapal, alat tangkap dan perhitungan-perhitungan pendekatan yang disesuaikan dengan karakteristik daerah pelayaran dari kapal tersebut. Hasil regresi ukuran utama adalah $\mathrm{Lpp}=\mathbf{1 7 . 1 1} \mathrm{m}, \mathrm{B}$ $=3.8 \mathrm{~m}, \mathrm{~T}=1.21 \mathrm{~m}, \mathrm{H}=1.60 \mathrm{~m}, \mathrm{Cb}=0.54$, dan $\mathrm{Vs}=9$ knot. Dari ukuran utama tersebut kemudian dibuat gambar rencana garis dan gambar rencana umum. Alat tangkap yang digunakan rawai tuna dasar. Sedangkan, Analisis Ekonomis dilakukan dengan Analisis Kelayakan Investasi. Kelayakan investasi dilakukan dengan biaya pembangunan $=\mathbf{R p}$ 1,221,490,193.04; NPV $=$ Rp 35,634,702.26; IRR = 14\%; dan $\mathbf{P P}=3.75$ tahun.
\end{abstract}

Kata Kunci-Kapal ikan, Rawai Tuna Dasar, Laut Selatan Malang, Analisis Teknis dan Ekonomis.

\section{PENDAHULUAN}

$I^{\top}$ NDONESIA merupakan negara kepulauan terbesar dengan jumlah pulau 17.508 buah dan memiliki garis pantai $81.000 \mathrm{~km}$ didominasi oleh wilayah laut yaitu kurang lebih 5,4 juta $\mathrm{km} 2$. Sehingga membuat membuat wilayah laut Indonesia kaya akan hasil laut yang melimpah [1].

Kekayaan dan potensi laut yang cukup besar di Samudra Indonesia, tak terkecuali di gugusan laut selatan Malang juga belum mampu memberikan kehidupan yang layak dan sejahtera bagi nelayan setempat, bahkan cenderung tetap menaungi komunitas nelayan di pesisir Pantai Sendangbiru di Kecamatan Sumbermanjing Wetan, Kabupaten Malang.

Padahal, potensi lautnya sangat beragam, bahkan jenis ikan tuna terbaik di lautan Indonesia, salah satunya berada di laut selatan Malang (Sendangbiru). Namun ironisnya masyarakat pesisir yang sebagian besar berprofesi sebagai nelayan yang hidup di pesisir pantai itu belum juga mampu bangkit dan perekonomiannya meningkat merupakan masyarakat termiskin di Indonesia. Sehingga perlu dipikirkan upaya untuk meningkatkan kesejahteran nelayan dengan mengupayakan meningkatkan pendapatan nelayan.

Nelayan di pesisir pantai masih menggunakan teknologi yang sangat sederhana. Besar kapalnya masih berukuran kurang dari 10 GT dengan alat tangkap berupa trammel net, gill net, dogol, tonda dan purse seine. Sedangkan untuk pelayaran laut sudah harus menggunakan kapal yang besarnya 30 GT keatas yang dilengkapi alat tangkap seperti rawai tuna, huhate, handline, pukat cincin, dan jaring insang. Oleh sebab itu perlu ada pengembangan kapal penangkap ikan beserta alat tangkapnya.

Selain memoderenisasi alat tangkap ikan, juga perlu memperhatikan kualitas hasil tangkapan itu sendiri agar memeiliki standart kualitas ekspor. Sekarang ini banyak perusahaan-perusahaan perikanan yang beroperasi di seluruh wilayah Indonesia sehingga dituntut mempunyai efisiensi yang baik dalam mengeksplorasi sumber daya laut yang ada. Dalam hal ini dipengaruhi oleh perencanaan kapal yang baik beserta alat tangkap yang tepat. Perencanaan kapal yang baik adalah perencanaan ukuran kapal ikan, data utama kapal, alat tangkap dan perhitungan-perhitungan pendekatan yang disesuaikan dengan karakteristik daerah pelayaran dari kapal tersebut.

Perencanaan kapal penangkap ikan yang baik sebagai terobosan baru dalam industri perikanan diharapkan dapat dioperasikan kapal yang memadai dan dapat menghasilkan produk ikan yang siap untuk dijual ke masyarakat dan jika memungkinkan dapat diekspor ke luar negeri. Sehingga pihak-pihak yang mengoperasikan kapal dapat memperoleh keuntungan yang sesuai dengan hasil produksinya.

Studi ini akan melakukan "Desain Kapal Ikan Di Perairan Laut Selatan Malang", yang diharapkan akan dapat memberikan gambaran kelayakan pembangunan kapal ikan.

\section{TINJAUAN PUSTAKA}

\section{A. Gambaran Umum Kapal Ikan}

Sedangkan menurut Undang-Undang RI No. 31 (2004), kapal perikanan adalah kapal, perahu atau alat apung lainnya yang dipergunakan untuk melakukan penangkapan ikan, mendukung operasi penangkapan ikan, pembudidayaan ikan, pengangkutan ikan, pengolahan ikan, pelatihan perikanan, dan penelitian atau eksplorasi perikanan.

Menurut pernyataan pihak Nomura \& Yamazaki (1977) [2], secara garis besar mengelompokkan kapal ikan ke dalam empat jenis yaitu:

a. Kapal penangkap ikan yang khusus digunakan dalam operasi penangkapan ikan atau mengumpulkan sumberdaya hayati perairan, antara lain kapal pukat udang, perahu pukat cincin, perahu jaring insang, perahu payang, perahu pancing tonda, kapal rawai, kapal huhate, dan sampan yang dipakai dalam mengumpul rumput laut, memancing dan lain lain.

b. Kapal induk adalah kapal yang dipakai sebagai tempat mengumpulkan ikan hasil tangkapan kapal penangkap 
ikan dan mengolahnya. Kapal induk juga berfungsi sebagai kapal pengangkut ikan. Hal ini berkaitan dengan pertimbangan efisiensi dan permodalan.

c. Kapal pengangkut ikan adalah kapal yang digunakan untuk mengangkut hasil perikanan dari kapal induk atau kapal penangkap ikan dari daerah penangkapan ke pelabuhan yang dikategorikan kapal pengangkut.

d. Kapal penelitian, pendidikan dan latihan adalah kapal ikan yang digunakan untuk keperluan penelitian, pendidikan dan latihan penangkapan, pada umumnya adalah kapal-kapal milik instansi atau dinas.

Sedangkan menurut pernyataan pihak Fyson (1985), kapal perikanan secara umum terdiri dari: kapal penangkap ikan, kapal pengangkut hasil tangkapan, kapal survei, kapal latih dan kapal pengawas perikanan [3][4].

a. Kapal Penangkap Ikan

Kapal penangkap ikan adalah kapal yang dikonstruksi dan digunakan khusus untuk menangkap ikan sesuai dengan alat penangkap dan teknik penangkapan ikan yang digunakan termasuk menampung, menyimpan dan mengawetkan.

b. Kapal Pengangkut Hasil Tangkapan

Kapal pengangkut hasil tangkapan adalah kapal yang dikonstruksi secara khusus, dilengkapi dengan palkah khusus yang digunakan untuk menampung, menyimpan, mengawetkan dan mengangkut ikan hasil tangkapan.

c. Kapal Survei

Kapal survei adalah kapal yang dikonstruksi khusus untuk melakukan kegiatan survei perikanan dan kelautan.

d. Kapal Latih

Kapal latih adalah kapal yang dikonstruksi khusus untuk pelatihan penangkapan ikan.

e.Kapal Pengawas Perikanan

Kapal pengawas perikanan adalah kapal yang dikonstruksi khusus untuk kegiatan pengawasan kapalkapal perikanan.

Sedangkan kapal ikan yang akan dibahas dalam studi ini adalah kapal ikan yang fungsinya untuk menagkap ikan.

\section{B. Jenis Penangkap Ikan}

Jenis penangkap yang digunakan dalam pemanfaatan sumber daya tuna disesuaikan dengan sifat dan tingkah laku ikan sasaran. Tuna merupakan ikan perenang cepat yang bergerombol. Selain itu Pemerintah juga melerang penggunaan alat penangkap ikan pukat hela atau trawls dan pukat Tarik atau seine nets (Peraturan Menteri Kelautan dan Perikanan Republik Indonesia Nomor 2 / Permen-KP / 2015). Oleh karena itu, alat penangkap ikan yang digunakan haruslah yang sesuai dengan perilaku ikan tersebut. Ada lima macam alat penangkap tuna, yaitu rawai tuna, huhate, handline. pukat cincin, dan jaring insang.

\section{1) Rawai tuna (tuna longline)}

Rawai tuna atau tuna longline adalah alat penangkap tuna yang paling efektif. Rawai tuna merupakan rangkaian sejumlah pancing yang dioperasikan sekaligus. Satu tuna longliner biasanya mengoperasikan $1.000-2.000$ mata pancing untuk sekali turun. Rawai tuna umumnya dioperasikan di laut lepas atau mencapai perairan samudera. Alat tangkap ini bersifat pasif, menanti umpan dimakan oleh ikan sasaran. Setelah pancing diturunkan ke perairan, lalu mesin kapal dimatikan. sehingga kapal dan alat tangkap akan hanyut mengikuti arah arus atau sering disebut drifting. Drifting berlangsung selama kurang lebih empat jam.
Selanjutnya mata pancing diangkat kembali ke atas kapal. Umpan longline harus bersifat atraktif. misalnya sisik ikan mengkilat, tahan di dalam air, dan tulang punggung kuat. Umpan dalam pengoperasian alat tangkap ini berfungsi sebagai alat pemikat ikan. Jenis umpan yang digunakan umumnya ikan pelagis kecil, seperti lemuru (Sardinella $s p$ ), layang (Decopterus $s p$ ), kembung (Rastrelliger $s p$ ), dan bandeng (Chanos chanos).

\section{2) Huhate (pole and line)}

Huhate atau pole and line khusus dipakai untuk menangkap cakalang. Tak heran jika alat ini sering disebut "pancing cakalang". Huhate dioperasikan sepanjang siang hari pada saat terdapat gerombolan ikan di sekitar kapal. Alat tangkap ini bersifat aktif. Kapal akan mengejar gerombolan ikan. Setelah gerombolan ikan berada di sekitar kapal, lalu diadakan pemancingan. Terdapat beberapa keunikan dari alat tangkap huhate. Bentuk mata pancing huhate tidak berkait seperti lazimnya mata pancing. Mata pancing huhate ditutupi bulu-bulu ayam atau potongan rafia yang halus agar tidak tampak oleh ikan. Bagian haluan kapal huhate mempunyai tangkap ini berfungsi sebagai alat pemikat ikan. Jenis umpan yang digunakan umumnya ikan pelagis kecil, seperti lemuru (Sardinella sp), layang (Decopterus sp), kembung (Rastrelliger $s p$ ).

\section{3) Pancing ulur (handline)}

Handline atau pancing ulur dioperasikan pada siang hari. Konstruksi pancing ulur sangat sederhana. Pada satu tali pancing utama dirangkaikan 2-10 mata pancing secara vertikal. Pengoperasian alat ini dibantu menggunakan rumpon sebagai alat pengumpul ikan. Pada saat pemancingan, satu rumpon dikelilingi oleh lima unit kapal, masing-masing kapal berisi 3-5 orang pemancing. Umpan yang digunakan adalah ikan segar yang dipotong-potong. Hasil tangkapan utama pancing ulur adalah tuna (Thunnus spp.).

\section{4) Pukat cincin (purse seine)}

Pukat cincin atau purse seine adalah sejenis jaring yang di bagian bawahnya dipasang sejumlah cincin atau gelang besi. Dewasa ini tidak terlalu banyak dilakukan penangkapan tuna menggunakan pukat cincin, kalau pun ada hanya berskala kecil. Pukat cincin dioperasikan dengan cara melingkarkan jaring terhadap gerombolan ikan. Pelingkaran dilakukan dengan cepat, kemudian secepatnya menarik purse line di antara cincin-cincin yang ada, sehingga jaring akan membentuk seperti mangkuk. Kecepatan tinggi diperlukan agar ikan tidak dapat meloloskan diri. Setelah ikan berada di dalam mangkuk jaring, lalu dilakukan pengambilan hasil tangkapan menggunakan serok atau penciduk. Pukat cincin dapat dioperasikan siang atau malam hari. Pengoperasian pada siang hari sering menggunakan rumpon atau payaos sebagai alat bantu pengumpul ikan. Sedangkan alat bantu pengumpul yang sering digunakan di malam hari adalah lampu, umumnya menggunakan lampu petromaks. Menurut pernyataan pihak Uktolseja (1987), payaos dapat menjaga atau membantu cakalang tetap berada di lokasi pemasangannya selama 340 hari.

\section{5) Jaring insang (gillnet)}

Jaring insang merupakan jaring berbentuk empat persegi panjang dengan ukuran mata yang sama di sepanjang jaring. Dinamakan jaring insang karena berdasarkar cara tertangkapnya, ikan terjerat di bagian insangnya pada mata jaring. Ukuran ikan yang tertangkap relatif seragam. Pengoperasian jaring insang dilakuka secara pasif. Setelah diturunkan ke perairan, kapal dan alat dibiarkan drifting, 
umumnya berlangsung selama 2-3 jam. Selanjutnya dilakukan pengangkat jaring sambil melepaskan ikan hasil tangkapan ke palka.

\section{Pendekatan Desain}

Dalam proses desain kapal dibutuhkan proses yang berulang-ulang untuk mendapatkan hasil optimal dengan cara mengatur dan menyeimbangkan parameter-parameter yang terkait dan diilustrasikan dalam Spiral Design. Di dalam diagram spiral design terdapat empat pembagian proses yaitu concept design, preliminary design, contract design, dan detail design [5].

\section{METODOLOGI PENELITIAN}

Secara umum prosedur pengerjaan penelitian ini dilakukan dengan langkah sesuai dengan diagram alir penelitian padaGambar 1 .

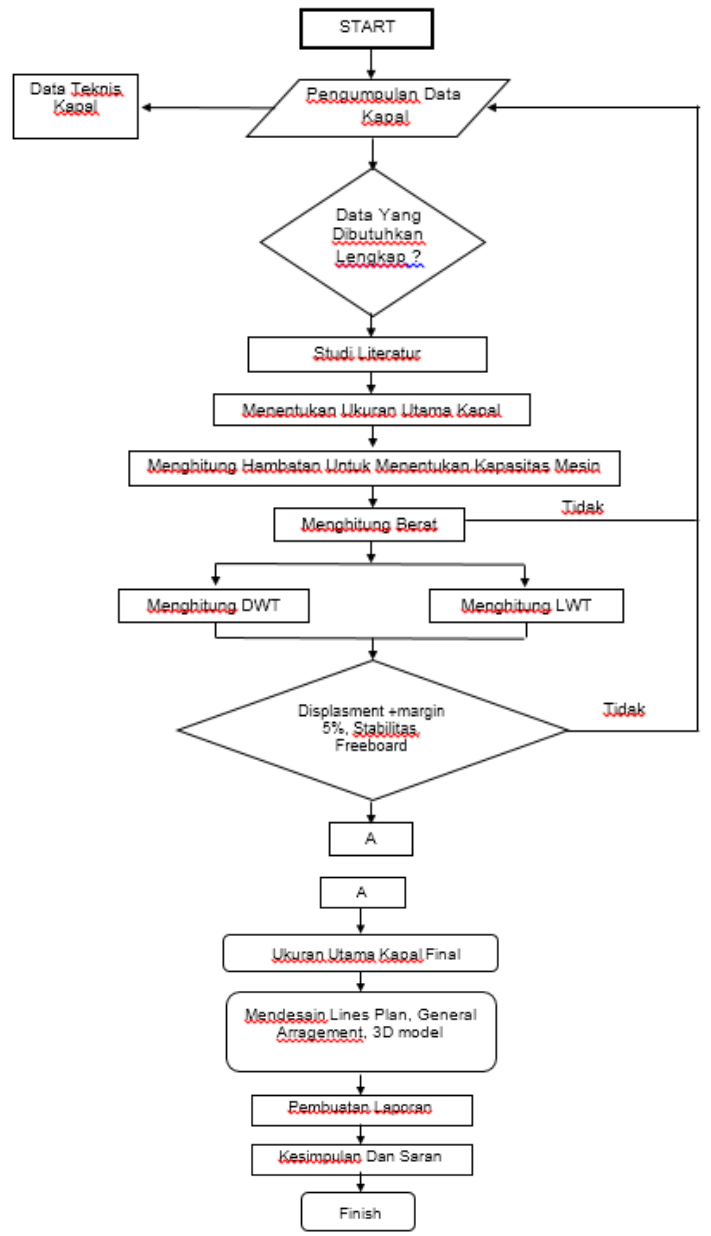

Gambar 1. Diagram Alir Pengerjaan

\section{Studi Literatur}

Tahap pertama yang dilakukan adalah studi literatur, yaitu mengumpulkan teori-teori yang berkaitan dalam penyelesaian studi.

$>$ Tahap Pengumpulan Data

Data yang dimaksud yaitu data yang relevan dan mencakup segala aspek yang berhubungan dalam pengerjaan studi.

Pengolahan Data

Tahap-tahap pengolahan yang harus dilakukan; menentukan payload, menentukan rute kapal, menentukan kecepatan dinas, dan menentukan ukuran utama.

$>$ Perhitungan Teknis dan Ekonomis
Perhitungan pada tahap ini meliputi; perhitungan hambatan, perhitungan propulsi, perhitungan berat dan titik berat, perhitungan stabilitas, perhitungan trim. Perhitungan ekonomis digunakan untuk memastikan kelayakan produksi dari kapal yang didesain.

> Pembuatan Rencana Garis dan Rencana Umum

Proses pembuatan rencana garis, dimana kelengkungankelengkungan dari bentuk badan kapal dapat dilihat. Desain rencana umum, yaitu gambar lengkap dari kapal yang didesain secara menyeluruh dari pandangan atas dan pandangan samping kapal.

$>$ Pembuatan 3D

Gambar desain 3D ini digunakan untuk memberikan penjelasan secara lebih riil dari desain rencana umum.

$>$ Kesimpulan dan Saran

Kesimpulan berupa jawaban atas tujuan dari studi. Sedangkan saran berisi tentang hal-hal yang dapat dikembangkan dari studi yang sedang dikerjakan.

\section{ANALISIS TEKNIS}

Kapal ikan didesain dengan berbagai perhitungan untuk mendapatkan desain yang sesuai dengan perairan disana. Selain itu, biaya pembangunan dan operasional juga diperhitungkan untuk mendapatkan keuntungan. Maka, perlu dilakukan penghitungan teknis serta analisis ekonomis kapal.

\section{A. Penentuan Payload}

Berdasarkan data statistik yang penulis dapatkan dari UPT P2SKP TPI Pondokdadap, Sendangbiru, Malang, jumlah volume hasil produksi tangkapan ikan di daerah Malang mengalami peningkatan tiap tahunnya. Hal tersebut dapat dilihat dari data dibawah ini dan kenaikan rata-rata tiap tahunnya yaitu sebesar $220,231.86 \mathrm{~kg} / \mathrm{th}$ atau 220 ton/th. Penentuan payload untuk kapal ikan yaitu rata-rata kenaikan per tahunnya dibagi menjadi 12 karena kapal akan melaut sebanyak 12 trip, yaitu menjadi 18,353 ton/trip. Untuk lebih jelasnya dapat dilihat pada Gambar2 dan Tabel 1 di bawah ini :

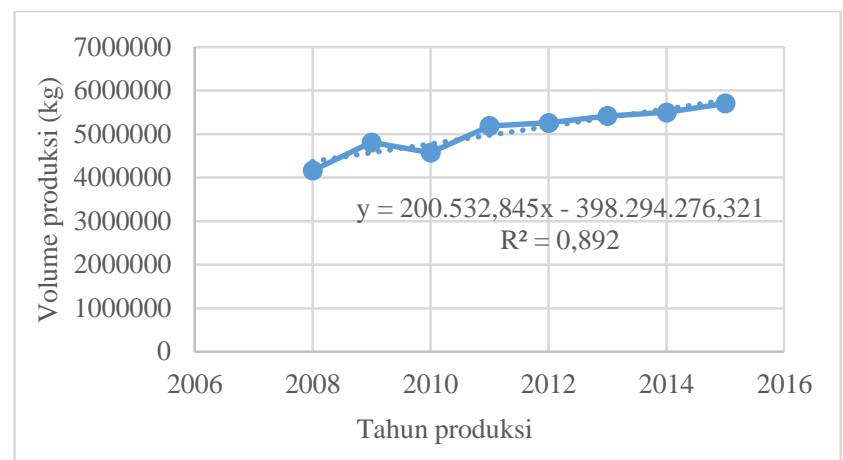

Gambar 2. Grafik Peningkatan Hasil Tangkap tahun 2008-2015

Tabel 1.

Produksi Hasil Tangkapan Ikan tahun 2008-2015

\begin{tabular}{ccc}
\hline \hline No & Tahun & Produksi $(\mathrm{kg})$ \\
\hline 1 & 2008 & 4163227 \\
2 & 2009 & 4809154 \\
3 & 2010 & 4576195 \\
4 & 2011 & 5187087 \\
5 & 2012 & 5261693 \\
6 & 2013 & 5418749 \\
7 & 2014 & 5499380 \\
8 & 2015 & 5704850 \\
\hline \hline
\end{tabular}




Jumlah 40620335

\begin{tabular}{cccc}
\hline \hline Berdasarkan selisih peningkatan hasil tangkap & 220231.86 & $\mathrm{~kg} / \mathrm{th}$ \\
ikan tiap tahun diperoleh rata-rata & 220 & ton/th \\
Dalam 1 tahun melakukan 12 trip & $=$ & 18.353 & ton/trip \\
\hline
\end{tabular}

\section{B. Penentuan Rute Kapal}

Penentuan besar muatan dan pemilihan rute perjalanan akan di jelaskan pada sub-bab di bawah ini. Hal ini akan memberikan gambaran owner requierements kepada designer mengenai payload dan panjangnya rute perjalan kapal ikan.

Berdasarkan potensi ikan yang ada di laut selatan malang maka di pilih rute pelayarannya seperti Gambar 1 bawah ini.

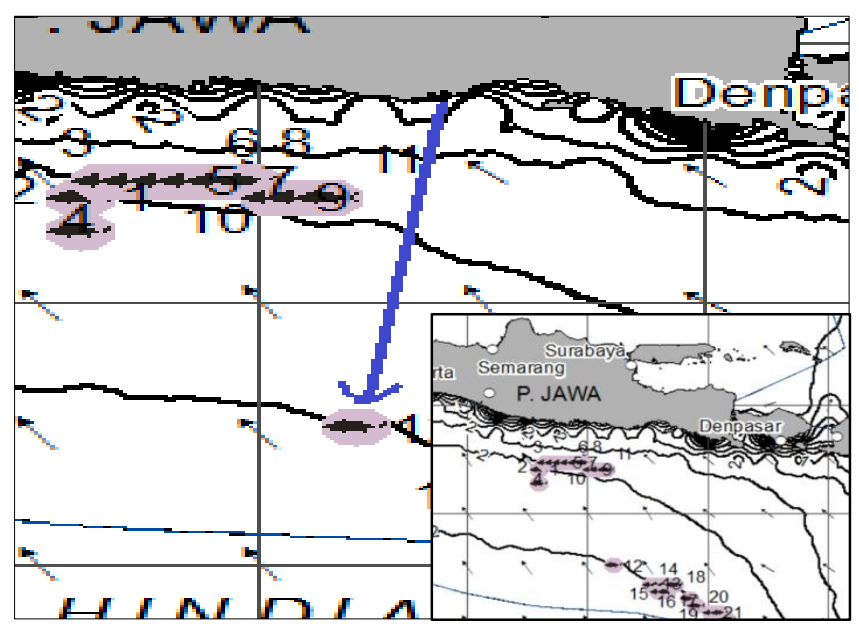

Gambar 1. Rute Kapal Ikan

\section{Penentuan Ukuran Utama}

Setelah payload dan kecepatan dinas ditentukan, maka dilakukan penetuan ukuran utama awal dari kapal yang didesain. Konsep penentuan ukuran utama kapal yang digunakan dalam pengerjaan studi ini yaitu pendekatan/metode dalam Fyson (1985) [3], dimana besarnya $L$ dapat ditentukan dengan melakukan regresi atau interpolasi linier terhadap fish hold capacity dan berat ikan dari data-data yang ada pada tabel Hubungan Antara Panjang Kapal dengan Fish hold capacity dan Berat ikan, didapatkan hasil ukuran utama kapal ikan :

Tabel 2.

Ukuran Utama Kapal

\begin{tabular}{cccc}
\hline \hline Length of Perpendicular (Lpp) & $=$ & 17.11 & $\mathrm{~m}$ \\
Length of Water Line (B) & $=$ & 17.789 & $\mathrm{~m}$ \\
Breadth Moulded (B) & $=$ & 3.80 & $\mathrm{~m}$ \\
Height Moulded (H) & $=$ & 1.69 & $\mathrm{~m}$ \\
Draft Moulded (T) & $=$ & 1.27 & $\mathrm{~m}$ \\
Velocity Service (VS) & $=$ & 9.00 & $\mathrm{Knot}$ \\
Cb & $=$ & 0.54 & \\
Displacement & $=$ & 49.420 & ton \\
\hline \hline
\end{tabular}

Tabel 3.

Perbandingan Rasio Ukuran Utama Kapal

\begin{tabular}{llcc}
\multicolumn{1}{c}{ Perbandingan } & & Rasio & Keterangan \\
$\mathrm{L} / \mathrm{B}(4,1-5,8)$ & $=$ & 4.500 & Accepted \\
$\mathrm{B} / \mathrm{T}(2-3)$ & $=$ & 3.000 & Accepted \\
$\mathrm{B} / \mathrm{H}(1,75-2.5)$ & $=$ & 2.311 & Accepted \\
$\mathrm{L} / \mathrm{H}(8,00-11,00)$ & $=$ & 10.100 & Accepted \\
\hline \hline
\end{tabular}

\section{Perhitungan Hambatan}

Perhitungan hambatan total dilakukan dengan metode yang didapat dari Fyson. Formula dalam metode tersebut adalah : hambatan total kapal penangkap ikan adalah :

$\mathrm{Rt}=\mathrm{Wr}+\mathrm{Ww}+\mathrm{Wat}+\mathrm{Wf}$

\section{$=1547.464$ Newton \\ $=1.547 \mathrm{kN}$}

Sedangkan, besar hambatan dari Maxsurf Resistance adalah $30.1 \mathrm{kN}$, sehingga hambatan yang diambil adalah $30.1 \mathrm{kN}$.

Setelah didapatkan nilai $\mathrm{R}_{\text {tot }}$ maka dilanjutkan dengan perhitungan EHP kemudian DHP kapal. Selanjutnya dilakukan penambahan koreksi $15 \%$ terhadap DHP. Perhitungan BHP (Delivery Horse Power) menurut (Fyson, 1985)[3] :

$$
\begin{array}{rl}
\text { BHP = DHP } \times(1+0.003) \\
=33.18 & \mathrm{HP} \\
=24.63 & \mathrm{~kW}
\end{array}
$$

Sedangkan, besar power dari Maxsurf Resistance adalah 139.29 kW, sehingga power yang diambil adalah 139.29 $\mathrm{kW}$.

Nilai BHP ini digunakan untuk menentukan mesin induk.

\section{E. Perhitungan Berat Kapal}

Pada perhitungan berat kapal ikan ini, ada dua kelompok utama yang dihitung yaitu LWT (Light Weight Tonnage) dan DWT (Dead Weight Tonnage) seperti terlihat pada Tabel 4 dan Tabel 5.

Tabel 4.

Rekapitulasi Berat LWT Kapal

\begin{tabular}{cccc}
\hline \hline \multicolumn{4}{c}{ Total Berat Bagian LWT } \\
\hline No & Komponen Berat Kapal Bagian LWT & Value & Unit \\
\hline 1 & Berat Lambung (hull) Kapal & 17.926 & ton \\
2 & Berat Geladak (deck) Kapal & 1.891 & ton \\
3 & Equipment \& Outfitting & 1.313 & ton \\
4 & Berat Atap Kapal & 0.330 & ton \\
5 & Berat Mesin & 1.111 & ton \\
6 & Berat bangunan atas & 0.865 & ton \\
& Total & 24.887 & 23.437 \\
\hline \hline
\end{tabular}

Tabel 5.

Rekapitulasi Berat DWT Kapal Total Berat Bagian DWT

\begin{tabular}{cccc}
\hline \hline & Total Berat Bagian DWT & & \\
No & Komponen Berat Kapal Bagian DWT & Value & Unit \\
\hline 1 & Berat Muatan & 19.391 & ton \\
2 & Berat Crew Kapal dan Barang Bawaan & 0.700 & ton \\
3 & Berat bahan bakar & 1.482 & ton \\
4 & Berat Air tawar & 1.960 & ton \\
5 & Berat Sewage & 1.372 & ton \\
6 & Berat Provision & 0.030 & ton \\
7 & Berat Minyak Pelumas & 0.038 & ton \\
8 & Berat Es & 0.035 & ton \\
Total & & 25.009 & ton \\
\hline \hline
\end{tabular}

Berdasarkan hasil reapitulasi LWT dan DWT diatas, kemudian dilakukan koreksi terhadap displacement.

$$
\begin{aligned}
\text { Correction } & =\Delta-(\mathbf{L W T}+\mathbf{D W T}) \\
& =0,794 \text { ton }(1.61 \%)
\end{aligned}
$$

Nilai displacement kapal yang lebih besar daripada jumlah LWT dan DWT. Hal ini menunjukkan bahwa gaya angkat kapal lebih besar dan kapal dapat mengapung.

\section{F. Perhitungan Trim Kapal}

Trim dapat didefinisikan sebagai kondisi kapal yang tidak even keel. Trim terjadi sebagai akibat dari tidak meratanya momen statis dari penyebaran gaya berat. Trim dibedakan menjadi dua, yaitu trim haluan dan trim buritan. Trim haluan terjadi apabila sarat haluan lebih tinggi daripada sarat buritan. Begitu juga sebaliknya untuk trim buritan. Dalam hal ini perhitungan trim di bantu dengan software Maxsurf Stability Enterprise.

Adapun batasan untuk trim adalah didasarkan pada selisih harga mutlak antara LCB dan LCG, dengan batasan $\leq$ Lpp/50 (NCVS,2009)[6]. Jika perhitungan tidak memenuhi syarat, maka dapat diperbaiki dengan mengubah / 
menggeser letak tangki-tangki yang telah direncanakan pada gambaran rencana umum awal. Untuk detail perhitungan pemeriksaan sarat dan trim kapal dapat dilihat di Tabel 6 di bawah ini.

Tabel 6.

Kondisi Trim pada Tiap Loadcase

\begin{tabular}{ccccc}
\hline \hline No & Kondisi & Batasan & Nilai & Status \\
\hline 1 & Loadcase 1 & 0.342 & 0.329 & Diterima \\
2 & Loadcase 2 & 0.342 & 0.159 & Diterima \\
3 & Loadcase 3 & 0.342 & 0.026 & Diterima \\
4 & Loadcase 4 & 0.342 & 0.313 & Diterima \\
5 & Loadcase 5 & 0.342 & 0.299 & Diterima \\
6 & Loadcase 6 & 0.342 & 0.158 & Diterima \\
\hline \hline
\end{tabular}

\section{G. Perhitungan Freeboard}

Kapal ikan merupakan kapal dengan panjang kurang dari $24 \mathrm{~m}$. Sehingga perhitungan lambung timbul kapal ikan menggunakan aturan Non-Convention Vessel Standart (NCVS) Indonesian Flagged.Berikut ini adalah input awal yang diperlukan untuk menghitung freeboard.

Tabel 7.

Freeboard Hasil dari Perhitungan

\begin{tabular}{ccc}
\hline \hline Lambung Timbul & Nilai & Satuan \\
\hline Lambung Timbul yang Syaratkan & 0.118 & $\mathrm{~m}$ \\
Lambung Timbul Sebenarnya & 0.43 & $\mathrm{~m}$ \\
\hline \hline
\end{tabular}

Karena actual freeboard pada Tabel IV.7 lebih besar sama dengan dari minimum freeboard, maka freeboard kapal yang direncanakan memenuhi persyaratan NCVS [7].

\section{H. Perhitungan Stabilitas}

Stabilitas adalah kriteria yang harus dipenuhi pada proses desain kapal untuk mengetahui keseimbangan kapal secara melintang atau oleng pada beberapa kriteria kondisi pemuatan (Loadcase). Kriteria stabilitas yang digunakan adalah kriteria stabilitas untuk kapal yang mengacu pada Intact Stability (IS) High Speed Craft (HSC) 2000 Annex 7 Multihull dan IMO A.749 (18) Chapter 3 [7].

Tabel 8 .

Hasil Analisis Stabilitas

\begin{tabular}{ccccccccc}
\hline \hline Data & Loadcase I & Loadcase II & Loadcase III & Loadcase IV & Loadcase V & Loadcase VI & Kriteria IMO & Kondisi \\
\hline $\mathrm{e}_{0-30^{\circ}}(\mathrm{m} . \mathrm{deg})$ & 14.15 & 14.39 & 14.71 & 14.70 & 14.541 & 14.86 & $\geq 3.151$ & Diterima \\
$\mathrm{e}^{0-40^{\circ}}(\mathrm{m} . \mathrm{deg})$ & 24.20 & 24.64 & 25.15 & 25.12 & 24.856 & 25.39 & $\geq 5.1566$ & Diterima \\
$\mathrm{e}^{30-40^{\circ}}$ (m.deg) & 10.05 & 10.25 & 10.48 & 10.42 & 10.316 & 10.52 & $\geq 1.7189$ & Diterima \\
$\mathrm{h}_{30^{\circ}}(\mathrm{m} . \mathrm{deg})$ & 1.23 & 1.27 & 1.30 & 1.28 & 1.281 & 1.32 & $\geq 0.2$ & Diterima \\
$\theta_{\max }(\mathrm{deg})$ & 65.5 & 65.5 & 65.5 & 61.8 & 61.8 & 74.5 & $\geq 25$ & Diterima \\
$\mathrm{GM}_{0}(\mathrm{~m})$ & 1.83 & 1.88 & 1.945 & 1.94 & 1.94 & 1.99 & $\geq 0.15$ & Diterima \\
\hline \hline
\end{tabular}

\section{Lines Plan \& General Arrangement}

Berdasarkan ukuran utama kapal, kemudian dibuat model lambung kapal menggunakan software sesuai dengan koefisien dan data hidrostatik pada perhitungan. Hasil desain kemudian di tampilkan kedalam 3 pandangan; body plan, sheer plan dan halfbreadth plan yang selanjutnya diedit menggunakan software sehingga didapatkan hasil akhir seperti pada Gambar 2.

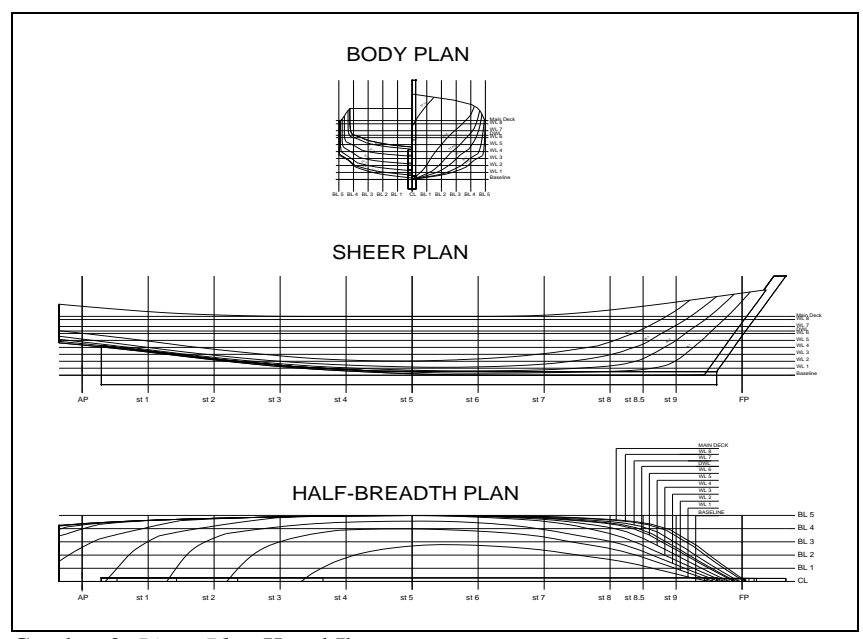

Gambar 2. Lines Plan Kapal Ikan

General Arrangement digunakan untuk merencanakan ruangan yang dibutuhkan sesuai dengan fungsi dan perlengkapan kapal. Desain dilakukan menggunakan software desain dengan memperhatikan penataan geladak supaya mampu mengakomodasi seluruh penumpang, nyaman, memiliki estetika yang tinggi serta sesuai dengan konsep yang diusung. Peletakan peralatan dan perabotan juga harus diperhatikan karena berpengaruh dengan perhitungan titik berat kapal. Hasil desain general arrangement adalah sebagai berikut:

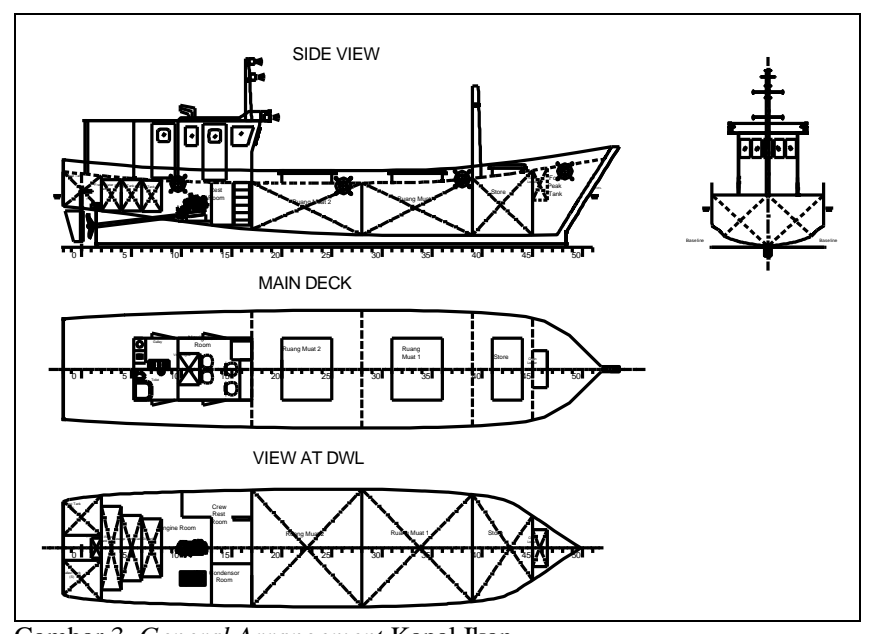

Gambar 3. General Arrangement Kapal Ikan 


\section{J. Desain Tiga Dimensi}

Dari desain General Arrangement yang sudah ada kemudian dilanjutkan dengan pembuatan desain tiga dimensi. Tujuan dari pembuatan desain ini adalah untuk memudahkan dalam memvisualisasikan bentuk dari Kapal Ikan ini. Desain dilakukan menggunakan software dengan hasil seeperti pada Gambar IV.5 :

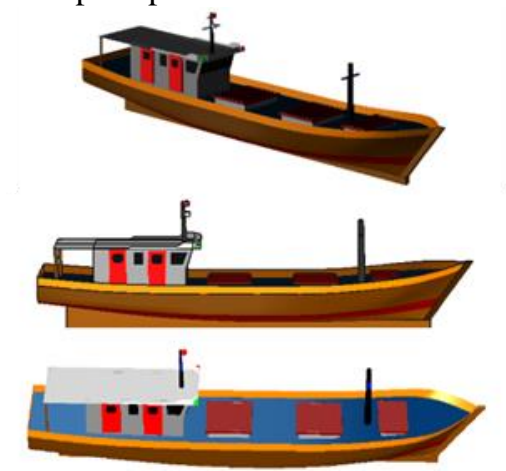

Gambar 4. Desain Kapal 3D

\section{K. Desain Alat Tangkap}

Selain membuat desain 3D Model, adapun desain alat tangkap yang digunakan untuk kapal ikan ini.

a. Long line

Long line adalah alat tangkap ikan yang terdiri dari rangkaian tali temali yang di bentangkan di perairan laut lepas. Pada setiap jarak tertentu dipasang tali cabang atau branch line dan dilengkapi pancing dan umpan.

b. Bagian-bagian dari alat tangkap long line

Seperti alat penangkap lainnya, satu unit long line terdiri dari kapal yang dirancang khusus, alat penangkap dan crew. Kapal-kapal tuna long line modern bagian belakang dari kapal ini telah dirancang dengan baik untuk mudah operasi dan pengaturan alat penangkap. Tuna long line sendiri pada umumnya terdiri dari :

- Pelampung (float)

- Tali Pelampung

- Tali Utama (main line)

- Tali cabang (branch line)

c. Alat Bantu Penangkapan

Ada beberapa alat bantu dari alat tangkap long line :

Line Hauler ,Line Arranger, Line Emiter, Branch Hauler, Line Setter, Side Roller, Long Line Spools, Radio Buoy, Long Line Block, Long Hook.

\section{Analisis Ekonomi}

Perhitungan keekonomian kapal ini bertujuan untuk mengetahui kelayakan investasi kapal berdasarkan perhitungan pemasukan dan pengeluaran [8][9].

$$
\begin{array}{ll}
\text { Building cost } & =\operatorname{Rp} 1,221,490,193.04 \\
\text { Operational cost } & =\operatorname{Rp~4,499,153,065.69~(per~tahun)~}
\end{array}
$$

$$
\begin{array}{ll}
\text { NPV } & =\text { Rp. } 35,634,702.26 \\
\text { Payback rate } & =3.75 \text { tahun }
\end{array}
$$

\section{KESIMPULAN}

Dari analisis, perhitungan teknis, dan proses mengenai desain kapal ikan yang beroperasi di perairan Laut Selatan Malang yang telah dilakukan pada tahapan sebelumnya maka dapat ditarik kesimpulan sebagi berikut :

1. Ukuran utama kapal penangkap ikan yang sesuai dengan perairan Laut Selatan Malang, yaitu

$$
\begin{aligned}
& \text { Loa }=18.8454 \mathrm{~m} \\
& \text { Lwl }=17.798 \mathrm{~m} \\
& \mathrm{Lpp}=17.11 \mathrm{~m} \\
& \mathrm{~B}=3.8 \mathrm{~m} \\
& \mathrm{H}=1.69 \mathrm{~m} \\
& \mathrm{~T}=1.27 \mathrm{~m} \\
& \mathrm{Vs}=9 \quad \mathrm{knot} \\
& \text { Crew }=7 \text { person } \\
& \mathrm{GT}=30 \mathrm{GT}
\end{aligned}
$$

2. Desain alat penangkap ikan kapal ikan menggunakan rawai tuna dasar atau long line, yaitu alat tangkap ikan yang terdiri dari rangkaian tali temali yang di bentangkan di perairan laut lepas. Pada setiap jarak tertentu dipasang tali cabang atau branch line dan dilengkapi pancing dan umpan.

3. Dari hasil analisis kelayakan investasi terkait perencanaan kapal ikan, didapat hasil sebagai berikut;
- Building Cost
: Rp 1,221,490,193.04
- Loan from bank
:Rp 793,968,625.5
- Loan Duration
: 10 Tahun
- Discount Rate from bank : $13.5 \%$
- Net Present Value (NPV) : Rp 35,634,702.26
- Internal Rate of Return (IRR) : $14 \%$
- Payback Period
:3.75 Tahun

\section{DAFTAR PUSTAKA}

[1] H. M. Barani, PEMIKIRAN PERCEPATAN PEMBANGUNAN. Bogor: Institut Pertanian Bogor, 2004.

[2] T. Nomura, M., \& Yamazaki, Fishing Techniques. Tokyo: Japan International Cooperation Agency, 1977.

[3] J. Fyson, Design of Small Fishing Vessels. Farnham: Fishing News Books Ltd, 1985.

[4] D. Darmawan, Desain Kapal Penangkap dan Pengolah Ikan Berbasis Optimisasi Biaya Operasional Kapal untuk Wilayah Perairan Pasuruan. Surabaya: Institut Teknologi Sepuluh Nopember, 2017.

[5] A. Aryansyah, "Desain Glass Bottom Catamaran Boat sebagai Sarana Wisata di Pulau Weh, Sabang," 2017.

[6] K. Perhubungan, Non-Convention Vessel Standart (NCVS) Indonesian Flagged. Jakarta: Kementrian Perhubungan Republik Indonesia, 2009.

[7] I. M. O. (IMO), International Convention for the Safety of Life at Sea, 1974, as amended (SOLAS 1974). London: IMO Publishing, 2009

[8] A. Gustian, "Studi Perancangan Trash Skimmer Boat di Perairan Teluk Jakarta," ITS, 2012.

[9] D. Watson, "Practical Ship Design," Elsevier, vol. 1, 1998. 